\title{
COMPLETE CONVERGENCE AND COMPLETE MOMENT CONVERGENCE FOR ARRAYS OF ROWWISE WIDELY ORTHANT DEPENDENT RANDOM VARIABLES AND AN APPLICATION
}

\author{
XIANG HUANG
}

Abstract. Some general results on complete convergence and complete moment convergence for arrays of rowwise widely orthant dependent random variables is established. As an application, the complete consistency for the estimators in non-parametric model is established.

Mathematics subject classification (2010): 60F15, $62 \mathrm{G} 05$.

Keywords and phrases: Complete convergence, complete moment convergence, complete consistency, non-parametric model, widely orthant dependent random variables.

\section{REFERENCES}

[1] P. L. Hsu, And H. RobBins, Complete convergence and the law of large numbers, Proceedings of the National Academy of Sciences 33 (1947), 25-31.

[2] Y. S. CHOw, On the rate of moment complete convergence of sample sums and extremes, Bulletin of the Institute of Mathematics Academia Sinica 16 (3) (1988), 177-201.

[3] K. WANG, Y. WANG, Q. GAO, Uniform asymptotics for the finite-time ruin probability of a new dependent risk model with a constant interest rate, Methodology and Computing in Applied Probability 15 (2013), 109-124.

[4] L. LiU, Precise large deviations for dependent random variables with heavy tails, Statistics and Probability Letters 79 (2009), 1290-1298.

[5] E. Lehmann, Some concepts of dependence, The Annals of Mathematical Statistics 37 (1966), 1137 1153.

[6] K. Joag-Dev, F. Proschan, Negative association of random variables with applications, The Annals of Statistics 11 (1983), 286-295.

[7] S. H. Sung, K. Buds abA, A. Volodin, Complete convergence for arrays of negatively dependent random variables, Informatics and its Applications 6 (4) (2012), 95-102.

[8] D. Qiu, P. Chen, R. G. Antonini, AND A. Volodin, On the complete convergence for arrays of rowwise extended negatively dependent random variables, Journal of the Korean Mathematical Society 50 (2) (2013), 379-392.

[9] S. SUNG, Complete convergence for weighted sums of negatively dependent random variables, Statistical Papers 53 (2012), 73-82.

[10] C. J. Stone, Consistent nonparametric regression, The Annals of Statistics 5 (1977), 595-645.

[11] A. A. GEORGIEV, Local properties of function fitting estimates with applications to system identification, In: W. Grossmann et al. (Eds.), Mathematical Statistics and Applications, Volume B, Proceedings 4th Pannonian Symposium on Mathematical Statistics, 4-10, September, 1983, Bad Tatzmannsdorf, Austria, Reidel, Dordrecht, 141-151, 1985.

[12] G. G. Rouss As, Consistent regression estimation with fixed design points under dependence conditions, Statistics and Probability Letters 8 (1989), 41-50.

[13] G. G. Rouss As, L. T. TRAn, D. A. IoAnnides, Fixed design regression for time series: asymptotic normality, Journal of Multivariate Analysis 40 (1992), 262-291.

[14] Y. FAN, Consistent nonparametric multiple regression for dependent heterogeneous processes: the fixed design case, Journal of Multivariate Analysis 33 (1990), 72-88. 
[15] H. Liang, B. Jing, Asymptotic properties for estimates of nonparametric regression models based on negatively associated sequences, Journal of Multivariate Analysis 95 (2005), 227-245.

[16] X. WAng, C. XU, T. C. Hu, A. Volodin, S. Hu, On complete convergence for widely orthant dependent random variables and its applications in nonparametric regression models, TEST, 23 (2014), 607-629.

[17] Q. Wu, Probability Limit Theory for Mixing Sequences, Science Press, Beijing, 2006. 